\title{
Age-related Cellular and Microstructural Changes in the Rotator Cuff Enthesis
}

Zeling Long ${ }^{1,2}$ Koichi Nakagawa1, Zhanwen Wang ${ }^{1,3}$, Peter C. Amadio ${ }^{1}$, Chunfeng Zhao ${ }^{1 *}$, Anne Gingery ${ }^{1,4^{*}}$

${ }^{1}$ Tendon and Soft Tissue Biomechanics Laboratory, Department of Orthopedic Surgery, Mayo Clinic, Rochester, MN

${ }^{2}$ Shenzhen Second People's Hospital, First Affiliated Hospital of Shenzhen University, Shenzhen, China

${ }^{3}$ Department of Orthopedics, The Second Xiangya Hospital of Central South University, Changsha, Hunan, China

${ }^{4}$ Department of Orthopaedic Surgery, Indiana University Medical School, Indianapolis, IN

Corresponding authors:

Chunfeng Zhao, MD

Department of Orthopedic Surgery, Mayo Clinic

200 1st St. SW, Rochester, MN 55905

Phone: 507-286- 0982

Email: zhao.chunfeng@mayo.edu

Anne Gingery, $\mathrm{PhD}$

Department of Orthopaedic Surgery, Indiana University School of Medicine

Medical Sciences Building 552

635 Barnhill Dr.

Indianapolis, IN 46202 Phone: 317-278-0085

Email: gingerya@iu.edu

Running Title: Rotator Cuff Age-related Cellular Changes

Author Contribution: ZL, PCA, CZ and AG contributed to conception, study design and data interpretation. ZL, KN, ZW performed experimental assays. ZL, AG completed data analysis. ZL and AG wrote manuscript. All authors contributed to revision of manuscript. All authors have read and approved this manuscript. 


\section{Abstract}

Rotator cuff injuries increase with age. The enthesis is the most frequent site of rotator cuff

injury and degeneration. Understanding age-related changes of the enthesis are essential to determine the mechanism of rotator cuff injuries, degeneration, and to guide mechanistically driven therapies. In this study, we explored age-related cellular changes of the rotator cuff enthesis in young, mature, and aged rats. Here we found that the aged enthesis is typified by an increased mineralized zone and decreased non-mineralized zone. Proliferation, migration, and colony forming potential of rotator cuff derived cells (RCECs) was attenuated with aging. The tenogenic and chondrogenic potential were significantly reduced, while the osteogenic potential increased in aged RCECs. The adipogenic potential increased in RCECs with age. This study explores the cellular differences found between young, mature, and aged rotator cuff enthesis cells and provides a basis for further delineation of mechanisms and potential therapeutics for rotator cuff injuries.

Keywords: Rotator cuff, enthesis, aging, tenogenesis, chondrogenesis 


\section{INTRODUCTION}

The incidence of musculoskeletal system diseases increases with age, resulting in severe joint pain, dysfunction and a large socioeconomic burden ${ }^{1}$. With age musculoskeletal tissues are prone to injury, degeneration, and slow healing.

Shoulder rotator cuff tears are one of the most common musculoskeletal clinical disorders, and the incidence increases rapidly after age $50^{1}$. There are 4.5 million shoulder injuries per year in the United States, of which $70 \%$ are due to rotator cuff tears ${ }^{2}$. Rotator cuff tears result in chronic pain, tissue dysfunction and reductions in mobility and activity, and thus impair healthy $\operatorname{aging}^{2 ; 3}$.

Rotator cuff injuries are often found at the tendon-bone interface (i.e., the enthesis). The enthesis is a composite tissue with a gradient of tendon, unmineralized fibrocartilage, mineralized fibrocartilage and bone ${ }^{1 ; 4 ; 5}$. This transitional zone from tendon to bone is typified by well-organized tendon fibers splayed out into thinner enthesis fibers which are firmly attached to the bone ${ }^{6-10}$. This structure exhibits unique functions in flexibility and reducing 
stress concentration between tendon (soft) and bone (hard) tissue, thus protecting the tendon

from fatigue injury at its insertion during shoulder movement ${ }^{11}$.

It is well understood that tendon and bone undergo degenerative processes with age. However,

it remains unclear how microstructure and cellular functional properties of the enthesis changes

with age. Rotator cuff tears can occur at any age but are increasingly evident with aging $1 ; 12$.

The repair and restoration of functionality of the enthesis after injury and degeneration remains

a significant clinical challenge.

In this study we hypothesized that the cells from rotator cuffs of aged individuals would have reduced proliferation, migration, tenogenic and osteogenic potential, as compared to cells from younger individuals. To explore this, we used a rat shoulder rotator cuff model. We isolated rotator cuff enthesis cells (RCECs) from young, mature, and aged rats. RCECs are a mixed population of cells that are found in the rotator cuff including tenogenic, chondrogenic and osteogenic cells. To our knowledge this is the first time that primary cells isolated from young, mature, and aged rotator cuff entheses have been assessed for proliferation, migration, colony formation and progenitor potential. 


\section{METHODS}

\section{Sample preparation}

Supraspinatus-enthesis-bone complex (supraspinatus were used here for its particular vulnerability in aging process ${ }^{13}$ ) were dissected from male Sprague Dawley rats immediately after sacrifice from other Institutional Animal Care and Uses Committee-approved studies. All samples were divided into three groups according to the rats' age: Young adult group (Y group 8-12 weeks), Mature group (M group 12-15 months) and Aged group (A group 20-24 months).

\section{Histology and image analysis}

Five samples from each group were fixed in 4\% paraformaldehyde and decalcified in decal solution for 10 days, then embedded in paraffin and cut into $\sim 7 \mu \mathrm{m}$ thick slide. H-E, Toluidine Blue and Picrosirius red staining were conducted following manufacturer's protocols. Slides were observed with 40 times magnification under a light microscope and images were collected by a camera mounted on the microscope. All measurements were performed by two independent researchers. One H\&E stained slide and one Toluidine blue stained slide from each sample were used for cell counting and area measurement. Briefly, the enthesis was 
divided into mineralized and non-mineralized zone by the tidemark, the region between tidemark and subchondral bone is mineralized zone and the region distal to the tidemark is nonmineralized zone. Both regions were outlined according to these criteria. Numbers of cells in each region were manually counted using Photoshop counting tool. Areas of mineralized/ nonmineralized region were quantified. For Picrosirius red staining, a polarized light scope was used to observe collagen fibers. Ten square regions were randomly selected from each slide and the grayscale value was measured using Image $\mathrm{J}$ software.

\section{Rotator cuff enthesis derived cells isolation}

Isolation of rotator cuff enthesis derived cell (RCECs) based on the method of Harada et al with minor modifications ${ }^{14 ; 15}$. Briefly RCECs were derived from four different individuals in each group. Immediately after sacrifice, the supraspinatus and infraspinatus tendon were cut off along the tendon-bone conjunction. The conjunction tissue was cut into small fragments and cultured in $75 \mathrm{~mm}$ plate with Dulbecco's modified eagle medium (DMEM, Thermo Fisher) containing 10\% fetal bovine serum (FBS, Sigma) and 1\% antibiotics at $37 \mathrm{C}$ with $5 \%$ humidified $\mathrm{CO} 2$. After two weeks of culture, the adherent cells attached, the fragments were 
removed, the culture medium was changed every three days and passaged when they reach $80 \%$

confluent until passenger three (P3).

\section{Proliferation and migration assay}

The proliferation and migration assays were conducted to evaluated. Briefly, RCECs $(n=4)$ were triple-plated in 12 well plates at 5x10 /well and incubated in IncuCyte (IncuCyte S3 Livecell analysis system) with automated image acquisition every 8 hours until confluence. A scratch was made using 100ul tips on each well and the migration and healing process was recorded by the IncuCyte every 8 hours for two days. Four locations were randomly selected to measure the healing area. The culture medium was changed every three days.

Cell counting kit-8 (Dojindo) assay was used to verify the proliferation assay result of IncuCyte. Briefly, RCECs were seeded in 96-well plates at a concentration of 1000 cells per well. Cells were stained with CCK-8 kit following the manufacturer's protocol. OD value at 450nm at day one, three and five were collected.

\section{Colony-formation Unit (CFU) assay}


The colony-forming unit assay was conducted to evaluate self-duplicate capacity. Briefly, RCECs $(n=4)$ were triple plated on $60 \mathrm{~mm}$ plates in triplicate at 100 cells per dish with media half-changed every three days. After ten days of cultivation, RCECs were fixed with 4\% PFA for 15 minutes and stained with crystal violet for 10 minutes (Sigma, St. Louis, MO) and counted using a light microscope.

\section{Osteogenic differentiation}

RCECs $(n=4)$ were triple-plated in 12 -well plates at a concentration of $5 \times 10^{4}$ cells/well and cultured with osteogenic differentiation medium (Gibco; StemPro ${ }^{\circledR}$ Osteogenesis Differentiation Kit). The cells cultured in basal culture medium served as controls. Culture medium was changed every three days. After 21 days of culture, osteogenic differentiation was evaluated by Alizarin red $\mathrm{S}$ staining of the mineralized matrix, lineage-specific genes (Osteopontin (Spp1), RUNX Family Transcription Factor 2 (Runx2), Osteocalcin (Bglap), primers sequences are listed in Supplementary 1) were evaluated by q-RT PCR.

\section{Adipogenic differentiation}


RCECs $(n=4)$ were triple-plated in 12 -well plates at a concentration of $5 \times 10^{4}$ cells/well and cultured with adipogenic differentiation medium (Gibco; StemPro ${ }^{\circledR}$ Adipogenesis Differentiation Kit). The cells cultured in basal culture medium served as controls. Culture medium was changed every three days. After 21-days-culturing, adipogenic differentiation was evaluated by Oil red-O staining of the cellular accumulation of neutral lipid vacuoles. Lineage-specific genes (Peroxisome Proliferator Activated Receptor Gamma (Pparg), adipocyte Protein 2 (Ap2), Lpl (lipid transfer protein 1), primers sequences are listed in Supplementary 1) were evaluated by q-RT PCR.

\section{Chondrogenic differentiation}

An aliquot of $8 \times 10^{5}$ RCECs ( $\mathrm{n}=4,3$ repeats) was spun down at $1500 \mathrm{rmp}$ for $3 \mathrm{~min}$ in a $15-\mathrm{ml}$ polypropylene tube to form a pellet. Cell pellets were cultured with chondrogenic differentiation medium (Gibco; StemPro ${ }^{\circledR}$ Chondrogenesis Differentiation Kit). The cells cultured in basal culture medium served as controls. Culture medium was changed every three days. After 21 days of culturing, chondrogenic differentiation was evaluated by toluidine blue staining, the pellets were embedded in OCT and cryo-sectioned for microscopy. Lineage- 
specific genes (collagen type II (Col-IIa1), SRY-Box Transcription Factor 9 (Sox9), collagen

$\mathrm{X}(\mathrm{Col}-\mathrm{X})$, primers sequences are listed in Supplementary 1) were analyzed by q-RT PCR.

\section{Tenogenic differentiation}

RCECs $(n=4)$ were triple-plated in 12 -well plates at a concentration of $5 \times 10^{4}$ cells $/$ well. and cultured with a supplement of 50ng/ml BMP12 (catalog\# 120-37, peproTech). The cells cultured in basal culture medium served as controls. Culture medium was changed every three days. After 14-days-culturing, tenogenic differentiation was evaluated by Picrosirius red staining of collagen deposition. Lineage-specific genes (Tenomodulin (Tnmd), Tenascin (Tnc), Decorin (Dcn), primers sequences are listed in Supplementary 1) were evaluated by qRT PCR.

\section{Gene Expression}

For gene expression analysis total RNA was isolated by Trizol (Invitrogen Life

Technologies; Thermo Fisher Scientific), and the RNA was reverse transcribed into cDNA

using an iScriptTM cDNA Synthesis Kit (Bio-Rad Laboratories, Hercules, CA, USA).

Quantitative PCR was performed with RT2 SYBR Green qPCR Master Mix (QIAGEN, 
Hilden, Germany), using an AC1000 Touch ${ }^{\mathrm{TM}}$ Thermal Cycler (Bio-Rad Laboratories) under the following cycling conditions: $95^{\circ} \mathrm{C}$ for 10 min followed by 40 cycles of amplification

$\left(95^{\circ} \mathrm{C}\right.$ for $15 \mathrm{~s}$ and $60^{\circ} \mathrm{C}$ for $\left.1 \mathrm{~min}\right)$. Expression levels were geomean normalized to $\beta$-actin,

GAPDH, and TBP. Samples were compared using $\Delta \Delta \mathrm{Ct}$ method.

\section{Statistical Analysis}

Numerical data are presented as mean \pm standard deviation and were tested for normality.

Statistical analyses of the histological quantification were performed using Kruskal-Wallis test.

Two-way analysis of variance (ANOVA) and multiple comparisons were used to compare the

CCK8, proliferation, migration, $\mathrm{CFU}$ and gene expression results among groups. Relative gene expressions were normalized to young non-differentiated group. Multiple comparison was conducted in two ways, 1) between young non-differentiated group and every other groups, 2) between each pair of differentiated group and non-differentiated group. All statistical analyses were performed with SPSS software (version 8.2.1; SPSS Inc); a P value of $<0.05$ was considered significant.

\section{RESULT}




\section{Histological Age Changes in Rotator Cuff}

Histological assessment of enthesis morphology, cellular fraction, mineralization, and collagen

alignment were assessed with H\&E, Toluidine blue and Picro Sirius staining. Samples were

divided into three groups according to age (young group: 8-12 weeks, mature group: 12-15

months, aged group: 20-24 months). In the young group the margins of the enthesis are well

defined with small and well-aligned cells. The tide mark dividing mineralized area and non-

mineralized area is clear and sharp (Figure 1A), large defined polysaccharide regions were

found in toluidine blue stained sections (Figure 1D). In the mature group, the structure of

enthesis remained intact, but with increased cellular disorder and decreased polysaccharide

expression (Figure 1B\&E). In the aged rotator cuff the cellular organization and tidemark were

increasingly disorganized and the fibro-chondrocytes in mineralized area enlarged and

disorganized. The polysaccharide region is substantially reduced (Figure 1C\&F).

Quantification of histological data is shown (Figure 1J). Data are reported as mean \pm SD. Cell

counts in the mineralized area are $372.7 \pm 202.87,220.4 \pm 63.11$ and $383.3 \pm 159.06$ in young,

mature, and aged groups respectively $(\mathrm{P}=0.0362)$. In the non-mineralized area, the cell counts

are $401 \pm 197.14,260 \pm 100.88$ and $182.5 \pm 89.23$ young, mature, and aged groups respectively 
$(\mathrm{P}=0.0094)$. Mineralized areas in young, mature, and aged groups are $0.069 \pm 0.024 \mathrm{~mm}^{2}, 0.042$

$\pm 0.015 \mathrm{~mm}^{2}$ and $0.072 \pm 0.023 \mathrm{~mm}^{2}(\mathrm{P}=0.0037)$ while non-mineralized areas are $0.072 \pm 0.020$

$\mathrm{mm}^{2}, 0.059 \pm 0.017 \mathrm{~mm}^{2}$ and $0.031 \pm 0.007 \mathrm{~mm}^{2}$ respectively $(\mathrm{P}=0.0001)$ (Figure $\left.1 \mathrm{~K}\right)$. The

thickness of the enthesis was measured as the mean of three randomly selected locations.

Mineralized thickness in these three groups are $0.092 \pm 0.026 \mathrm{~mm}, 0.055 \pm 0.011 \mathrm{~mm}$ and 0.125

$\pm 0.027 \mathrm{~mm}(\mathrm{P}<0.0001)$ in the young, mature, and aged groups. Non-mineralized area, they are

$0.109 \pm 0.021 \mathrm{~mm}, 0.083 \pm 0.021 \mathrm{~mm}$ and $0.057 \pm 0.019 \mathrm{~mm}(\mathrm{P}=0.0004)$ respectively (Figure

1L). Brightness greyscale values were measured using Image $\mathrm{J}$ software based of picrosirius

red staining figures (Figure 1GHI). They are 61.51 $\pm 23.54,63.41 \pm 25.14$ and $69.38 \pm 31.71$

for young, mature, and aged groups $(\mathrm{P}=0.1554)$.

\section{Proliferation and wound healing assay}

Rotator cuff enthesis cells (RCECs) were isolated and cultured from young, mature, and aged

rats. Cells were cultured and assessed using proliferation and migration assays. After 10-14

days of culture, radial clustered, spindle-shaped cells were observed, exhibiting a fibroblast-

like morphology. This feature is clear in young group (Figure 3A) but diminished with age. In

the aged group, the RCECs are rounded, enlarged and isolated morphology (Figure $3 \mathrm{C}$ ). 
Next, we assessed proliferation potential of passage three RCECs. Here we found that young

RCECs showed a significantly higher proliferation rate as compared to mature and aged

RCECs as evaluated by CCK8 proliferation assay (Figure 2B) and fold change assessed by IncuCyte phase object confluence analysis (Figure 2C).

We further assessed RCECs migration potential. Our migration assay shows that young RCECs have significantly increased migration rate as compared to mature and aged cells. After 48 hours of culture, seven out of sixteen selected areas fully bridged the scratched region in young RCECs cultures, compared to the mature RCEC's highest migration (of 59\% healing area) and aged RCECs of $40 \%$ healing area (Figure $2 \mathrm{AD}$ ).

\section{Colony-forming Units}

Colony forming units (CFU) are another measure of proliferative potential. The proportion of cells with self-replicating potential was determined by counting the number of colonies, to evaluate the overall cell proliferation potential. Here we assessed the ability of RCECs to form CFU (Figure 2E). Young RCECs formed significantly more CFUs than mature and aged RCECs. The mean colony formation unit for young RCECs was $26.33 \pm 4.89$ units per 100 
cells, significantly higher than both the mature $(12.17 \pm 10.51$ units per 100 cells, $\mathrm{P}<0.01)$ and aged groups $(3.33 \pm 2.06$ units per 100 cells, $\mathrm{P}<0.001)$ (Figure $2 \mathrm{~F})$. Further we noted that the size of colonies formed in young group was larger than those in mature and aged RCECs.

\section{Multi-differentiation Potential}

RCECs in all three age groups had the ability to differentiated in osteogenic, adipogenic and chondrogenic lineages. However, mature RCECs and aged RCECs did not differentiation to tenogenic lineage in contrast to young RCECs.

Calcium accumulation, demonstrated by Alizarin red staining, was formed in all ages of osteogenic RCECs (Figure 3DEF). Lineage-specific osteogenic genes (Spp1, Runx2, Bglap) were up-regulated in all differentiated groups, interactions between age and treatment (osteogenesis) were significant (Figure 3GHI).

Adipogenesis was verified by Oil red staining, red-stained lipids were found in all ages of adipogenic RCECs (Figure 4DEF). Lineage-specific adipogenic genes (Pparg, Ap2, Lpl) were up-regulated in all differentiated groups, interactions between age and treatment (adipogenesis) were significant (Figure $4 \mathrm{GHI}$ ). 
Chondrogenesis of RCECs was assessed by Alcian blue staining and mRNA expression of lineage-specific genes (Collagen II, Collagen X, Sox9). Before chondrogenic inducement, RCECs demonstrated a connected, reticular fibroblast-like morphology. After 21 days of chondrogenic treatment, RCECs exhibited rounded, granular chondrocyte-like phenotype in all ages of chondrogenic groups (Figure 5DEF). Lineage-specific chondrogenic genes were upregulated in young and mature chondrogenic RCECs. However, Col-II and Sox 9 were not upregulated in aged chondrogenic RCECs, only COL-X was up-regulated in aged chondrogenic RCECs. Interactions between age and chondrogenic treatment were significant (Figure 5GHI). RCECs were treated with BMP12 for 14 days a noted tenogenic inducer ${ }^{16-18}$. Picrosirius red collagen staining was performed to visualize the tenogenic differentiation. Young RCECs had strong red collagen staining, and which was enhanced after BMP12 induction (Figure A, D). However, there was less staining in the mature and aged groups, nor after BMP12 treatment. The aged RCECs displays enlarged, rounded, isolated morphology before treatment (Figure 6C), but become more spindle-shaped and clustered after BMP12 induction (Figure 6F). Lineage-specific gene Tnmd expressed significantly higher in the young RCECs with or without linage induction (Figure 6G) and were up-regulated in BMP12 tenogenic RCECs 
induction in the mature and aged groups. Interestingly, for Tnmd, there were no significant interactions between age and treatment, while both separately were significant. Tnc, interactions between age and treatment were not significant (Figure 6H). The expression of Dcn was up regulated after BMP12 induction in young RCECs and aged RCECs. Expression of Den was much lower in mature and aged RCECs regardless of BMP12 induction. Interactions between age and treatment were significant (Figure 6I).

\section{DISCUSSION}

This study explored the age-related cellular and microstructural changes found in the rotator

cuff enthesis using a rat model. Histological assessment showed the typical gradient structure of entheses in our models including the fibrous structure of tendon, non-mineralized fibrocartilage, and mineralized fibrocartilage and bone. With age well-aligned collagen fibers in the rotator cuff enthesis become increasingly disorganized. Further with age, this enthesis zone narrows, substantially decreasing the contact area between tendon and bone.

There is a clear boundary between bone tissue and fibrocartilage in the enthesis, which is more obvious with toluidine blue staining. In fibrocartilage, the polysaccharide in the matrix stains 
blue, which is not seen in the bone area. Chondrocytes/fibro-chondrocytes synthesize polysaccharide. Polysaccharides allow the ECM to be permeable and able to absorb more water, which helps to resist compressive loads. With age the polysaccharide area diminishes, resulting in poor mechanical performance.

The fibrocartilage is further divided into mineralized and non-mineralized areas, separated by the tidemark $^{19}$. Cells in mineralized fibrocartilage are more differentiated, rounded and hypertrophic ${ }^{20 ; 21}$, while in non-mineralized fibrocartilage, they are smaller and aligned in columns, similar to immature chondrocytes $22 ; 23$. In our findings, the non-mineralized fibrocartilage and cellularity decrease with age. The non-mineralized fibrocartilage plays an important role in dissipating the stress upon loading ${ }^{24-26}$, so a decrease in the size of this zone may result in a greater risk of injury. Further the reduced number of cells in non-mineralized fibrocartilage may indicate reduced regeneration potential. Besides, the tide mark becomes increasing disorganized with age, which reflect the resultant tears and attenuated mechanical properties ${ }^{27}$. Collectively, these structural changes weaken the elastic buffer effect of the enthesis, making it more fragile and prone to injury. 
Structural changes are mitigated in large part by cellular changes that contribute to the rotator cuff injuries that are found with aging. There are three dominating aging cellular changes, a) decreased proliferation rate, b) loss of wound-healing/migration capability and c) shifted differentiation potential.

Uniquely in this study, we isolated primary cells from the rotator cuff enthesis, instead of focusing on specific cell types, as this more accurately represents the cellular diversity found in the enthesis. The cell types can include cells from bone, cartilage, fibrocartilage, tendon, stromal progenitors and adipose tissue. Assessing the different lineages separately limits the ability to assess the overall impact of this composite tissue. The assessment of the primary enthesis cells provides a broader picture of enthesis as an integrated tissue, which is the functional unit of the tendon-bone interface. The primary RCECs were assessed for migration, proliferation, and differentiation potential. Here we found that, RCECs derived from mature and aged rats have significantly decreased proliferative, colony forming, and migrating potential as compared to the RCECs from young animals. In the young enthesis when microwounding occurs ${ }^{28}$, the RCECs can quickly proliferate and repair the damage, so as to avoid further tears of the rotator cuff. However, in the aged enthesis, this ability is weakened, the 
damage cannot be repaired effectively in time, consequently the rotator cuff tear can more

readily propagate.

Assessment of RCECs in different age groups showed that each group retained their multilineage differentiation potentials, however the potential for differentiation shifted. Significant interactions were found between treatment and age in these differentiation experiments. Mature and aged RCECs demonstrated high differentiative potential towards osteocyte and adipocyte, as shown in the lineage specific gene expression and histological staining.

After chondrogenic differentiation, lineage specific markers of RCECs increased significantly in young and middle-aged groups, but not in aged group. Only Col-X was up-regulated in aged chondrogenic RCECs. This type of collagen is synthesized by hypertrophic chondrocytes, which is evident in aged chondrocytes ${ }^{20 ; 21 ; 29}$.

Assessing the role of tenogenic lineage capacity is more challenging. To date there is no established method for this tenogenic assessment. Some reports have suggested tenogenic induction using BMP12 ${ }^{16-18}$. Although mature and aged RCECs had some tenogenic potential, tenogenic markers were largely attenuated in mature and aged RCECs. It is important to note 
that among all tenogenic markers, Tnmd tends to be the most representative biomarker for stemness ${ }^{30-33}$. The significant loss of Tnmd in mature and aged RCECs is an essential indicator of the loss tenocyte related gene expression and perhaps differentiation ${ }^{34 ; 35}$. Further, the loss of Tnmd can cause premature tendon aging by dysregulating the collagen fibrinogenesis and reducing cell proliferation ${ }^{36}{ }^{37}$. Interestingly, Tnmd was not up regulated in young RCECs after BMP12 induction. It is possible that RCECs in young group show a strong phenotype of tendon/tendon stem cells already. In previous studies, Tnc was used as a marker for tendon differentiation $^{38 ; 39}$, but Tnc is not solely expressed in tendon, being highly expressed in bone and cartilage as well ${ }^{40 ; 41}$. Our results show that Tnc was not up regulated after BMP12 induction.

The results of the multi-differentiation assays showed that in the aging process, the RCECs gradually lose their chondrogenic and tenogenic potentials. This makes it difficult to form the typical enthesis structure with four distinct zones in the process repair and regeneration, especially the fibrocartilage structure.

The age-related phenotypic changes of mixed cell populations at the enthesis have not been assessed in previous studies, to the best of our knowledge. Understanding cellular changes that 
occur with age will aid in the development of novel targets and therapeutic approaches to improve tendon to bone healing that is required for clinical repair including shoulder rotator cuff injuries. A possible strategy to attenuate the damage caused by aging would be the shifting of the aged osteogenic/adipogenic enthesis phenotype to a more fibrogenic phenotype. Approaches to change cellular phenotypes include cell fusion ${ }^{42}$, nuclear transfer ${ }^{43}$, and micro vesicles-based therapy ${ }^{44}$. These cell-derived vesicles have been shown to alter cellular phenotypes in many different cells and tissue combinations ${ }^{45-49}$. Our future work will focus on determining if promoting fibro-tenogenic differentiation will aid in the regeneration in aged rotator cuff enthesis which may help reduce age-related injuries and improve native tissue regeneration after repair.

During aging the cells of the rotator cuff enthesis showed declined migration, proliferation and colony forming potential. Further with age the cells of the enthesis have increased adipogenic and osteogenic induction, whereas tendon markers are reduced. These results correspond to the increased fatty osteogenic infiltration found in the enthesis with aging. Taken together these cellular shifts within the enthesis may be responsible for both the frequent rotator cuff injuries and the limited healing and regeneration that is found in patients as they age. 
bioRxiv preprint doi: https://doi.org/10.1101/2021.07.22.452068; this version posted July 23, 2021. The copyright holder for this preprint

(which was not certified by peer review) is the author/funder. All rights reserved. No reuse allowed without permission.

\section{Conflict of Interest}

There are no author conflicts to report.

\section{Acknowledgements}

This study was funded by a NIH/NIAMS AR07381 grant, Mayo Clinic Orthopedic Surgery

Career Development grant, China Scholarship Council, and the Mayo Clinic Foundation. 


\section{REFERENCES}

1. Tashjian RZ. 2012. Epidemiology, natural history, and indications for treatment of rotator cuff tears. Clin Sports Med 31:589-604.

2. Longo UG, Risi Ambrogioni L, Candela V, et al. 2021. Conservative versus surgical management for patients with rotator cuff tears: a systematic review and METAanalysis. BMC musculoskeletal disorders 22:50.

3. Yamaguchi K, Ditsios K, Middleton WD, et al. 2006. The demographic and morphological features of rotator cuff disease. A comparison of asymptomatic and symptomatic shoulders. The Journal of bone and joint surgery 88:1699-1704.

4. Yamamoto A, Takagishi K, Osawa T, et al. 2010. Prevalence and risk factors of a rotator cuff tear in the general population. J Shoulder Elbow Surg 19:116-120.

5. Zelzer E, Blitz E, Killian ML, et al. 2014. Tendon-to-bone attachment: from development to maturity Birth Defects Res C Embryo Today 102:101-112.

6. M. Benjamin. 2006. Where tendons and ligaments meet bone: attachment sites ('entheses') in relation to exercise and/or mechanical load. J Anat. 
7. Rossetti L, Kuntz LA, Kunold E, et al. 2017. The microstructure and micromechanics of the tendon-bone insertion. Nature materials 16:664-670.

8. Deymier AC, Schwartz AG, Cai Z, et al. 2019. The multiscale structural and mechanical effects of mouse supraspinatus muscle unloading on the mature enthesis Acta biomaterialia 83:302-313.

9. Schwartz AG, Pasteris JD, Genin GM, et al. 2012. Mineral distributions at the developing tendon enthesis. PloS one 7:e48630.

10. Genin GM, Kent A, Birman V, et al. 2009. Functional grading of mineral and collagen in the attachment of tendon to bone. Biophysical journal 97:976-985.

11. Benjamin M, McGonagle D. 2009. Basic concepts of enthesis biology and immunology. The Journal of rheumatology Supplement 83:12-13.

12. Wani Z, Abdulla M, Habeebullah A, et al. 2016. Rotator cuff tears: Review of epidemiology, clinical assessment and operative treatment. Trauma 18:190-204.

13. Benson RT, McDonnell SM, Knowles HJ, et al. 2010. Tendinopathy and tears of the rotator cuff are associated with hypoxia and apoptosis. J Bone Joint Surg Br 92:448453. 
14. Harada Y, Mifune Y, Inui A, et al. 2017. Rotator cuff repair using cell sheets derived from human rotator cuff in a rat model. J Orthop Res 35:289-296.

15. Nagura I, Kokubu T, Mifune Y, et al. 2016. Characterization of progenitor cells derived from torn human rotator cuff tendons by gene expression patterns of chondrogenesis, osteogenesis, and adipogenesis. J Orthop Surg Res 11:40.

16. Shen H, Gelberman RH, Silva MJ, et al. 2013. BMP12 induces tenogenic differentiation of adipose-derived stromal cells. PloS one 8.

17. Dai L, Hu X, Zhang X, et al. 2015. Different tenogenic differentiation capacities of different mesenchymal stem cells in the presence of BMP-12. Journal of translational medicine 13:200.

18. Zarychta-Wiśniewska W, Burdzinska A, Kulesza A, et al. 2017. Bmp-12 activates tenogenic pathway in human adipose stem cells and affects their immunomodulatory and secretory properties. BMC cell biology 18:1-14.

19. Benjamin M, Kumai T, Milz S, et al. 2002. The skeletal attachment of tendons--tendon "entheses" Comparative biochemistry and physiology Part A, Molecular \& integrative physiology 133:931-945. 
20. Sun MM, Beier F. 2014. Chondrocyte hypertrophy in skeletal development, growth, and disease. Birth Defects Res C Embryo Today 102:74-82.

21. Singh P, Marcu KB, Goldring MB, et al. 2019. Phenotypic instability of chondrocytes in osteoarthritis: on a path to hypertrophy. Ann N Y Acad Sci 1442:17-34.

22. Wei X, Hu M, Mishina Y, et al. 2016. Developmental Regulation of the Growth Plate and Cranial Synchondrosis. Journal of dental research 95:1221-1229.

23. Tew S, Redman S, Kwan A, et al. 2001. Differences in repair responses between immature and mature cartilage. Clin Orthop Relat Res:S142-152.

24. Benjamin M, Ralphs JR. 2001. Entheses--the bony attachments of tendons and ligaments. Ital J Anat Embryol 106:151-157.

25. Benjamin M, Ralphs JR. 1998. Fibrocartilage in tendons and ligaments--an adaptation to compressive load. J Anat 193 ( Pt 4):481-494.

26. Lu HH, Thomopoulos S. 2013. Functional attachment of soft tissues to bone: development, healing, and tissue engineering. Annual review of biomedical engineering 15:201-226. 
27. Schultz M, Molligan J, Schon L, et al. 2015. Pathology of the calcified zone of articular cartilage in post-traumatic osteoarthritis in rat knees. PloS one 10:e0120949-e0120949.

28. Nho SJ, Yadav H, Shindle MK, et al. 2008. Rotator cuff degeneration: etiology and pathogenesis The American journal of sports medicine 36:987-993.

29. von der Mark K, Kirsch T, Nerlich A, et al. 1992. Type X collagen synthesis in human osteoarthritic cartilage. Indication of chondrocyte hypertrophy. Arthritis and rheumatism 35:806-811.

30. Hou Y, Ni M, Lin S, et al. 2017. Tenomodulin highly expressing MSCs as a better cell source for tendon injury healing. Oncotarget 8:77424-77435.

31. Lui PP, Rui YF, Ni M, et al. 2011. Tenogenic differentiation of stem cells for tendon repair-what is the current evidence? J Tissue Eng Regen Med 5:e144-163.

32. Jiang Y, Shi Y, He J, et al. 2017. Enhanced tenogenic differentiation and tendon-like tissue formation by tenomodulin overexpression in murine mesenchymal stem cells. J Tissue Eng Regen Med 11:2525-2536.

33. Shi Y, Xiong Y, Jiang Y, et al. 2017. Conditional tenomodulin overexpression favors tenogenic lineage differentiation of transgenic mouse derived cells. Gene 598:9-19. 
34. Alberton P, Dex S, Popov C, et al. 2014. Loss of Tenomodulin Results in Reduced SelfRenewal and Augmented Senescence of Tendon Stem/Progenitor Cells. Stem cells and development 24:597-609.

35. Jiang Y, Shi Y, He J, et al. 2017. Enhanced tenogenic differentiation and tendon-like tissue formation by tenomodulin overexpression in murine mesenchymal stem cells. J Tissue Eng Regen Med 11:2525-2536.

36. Shukunami C, Takimoto A, Oro M, et al. 2006. Scleraxis positively regulates the expression of tenomodulin, a differentiation marker of tenocytes. Developmental biology 298:234-247.

37. Docheva D, Hunziker EB, Fassler R, et al. 2005. Tenomodulin is necessary for tenocyte proliferation and tendon maturation. Mol Cell Biol 25:699-705.

38. Liu Q, Yu Y, Reisdorf RL, et al. 2019. Engineered tendon-fibrocartilage-bone composite and bone marrow-derived mesenchymal stem cell sheet augmentation promotes rotator cuff healing in a non-weight-bearing canine model. Biomaterials 192:189-198. 
39. Liu Q, Zhu Y, Qi J, et al. 2019. Isolation and characterization of turkey bone marrowderived mesenchymal stem cells. J Orthop Res 37:1419-1428.

40. Webb CM, Zaman G, Mosley JR, et al. 1997. Expression of tenascin-C in bones responding to mechanical load. J Bone Miner Res 12:52-58.

41. Jones PL, Jones FS. 2000. Tenascin-C in development and disease: gene regulation and cell function. Matrix Biol 19:581-596.

42. Quesenberry PJ, Dooner G, Dooner M, et al. 2005. Ignoratio elenchi: red herrings in stem cell research. Science (New York, NY 308:1121-1122.

43. Gurdon JB, Byrne JA. 2003. The first half-century of nuclear transplantation. Proceedings of the National Academy of Sciences 100:8048-8052.

44. Quesenberry PJ, Aliotta JM. 2010. Cellular phenotype switching and microvesicles. Advanced drug delivery reviews 62:1141-1148.

45. Rozmyslowicz T, Majka M, Kijowski J, et al. 2003. Platelet-and megakaryocytederived microparticles transfer CXCR4 receptor to CXCR4-null cells and make them susceptible to infection by X4-HIV. Aids 17:33-42. 
46. Rialland P, Lankar D, Raposo G, et al. 2006. BCR-bound antigen is targeted to exosomes in human follicular lymphoma B-cells 1. Biology of the Cell 98:491-501.

47. Håkelien A-M, Landsverk HB, Robl JM, et al. 2002. Reprogramming fibroblasts to express T-cell functions using cell extracts. Nat Biotechnol 20:460-466.

48. Ratajczak J, Miekus K, Kucia M, et al. 2006. Embryonic stem cell-derived microvesicles reprogram hematopoietic progenitors: evidence for horizontal transfer of mRNA and protein delivery. Leukemia 20:847-856.

49. Deregibus MC, Cantaluppi V, Calogero R, et al. 2007. Endothelial progenitor cellderived microvesicles activate an angiogenic program in endothelial cells by a horizontal transfer of mRNA. Blood, The Journal of the American Society of Hematology 110:2440-2448. 


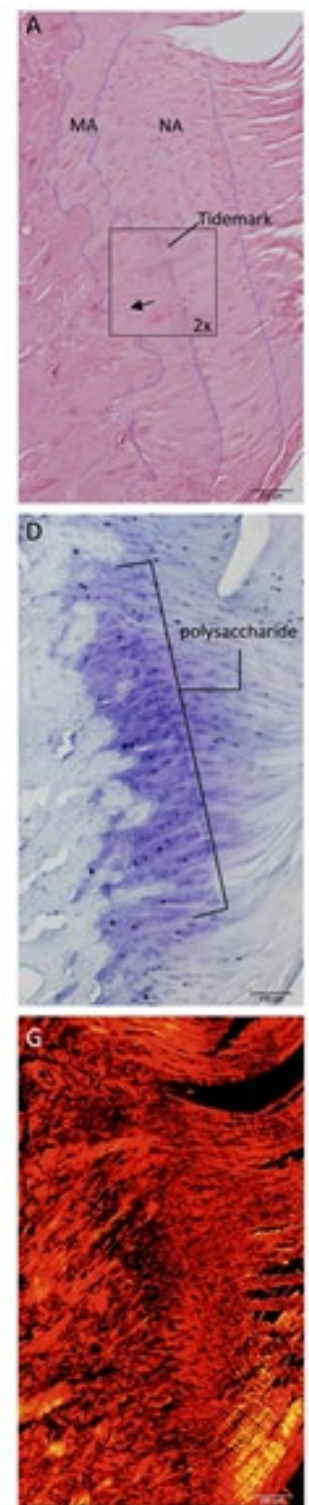

Young
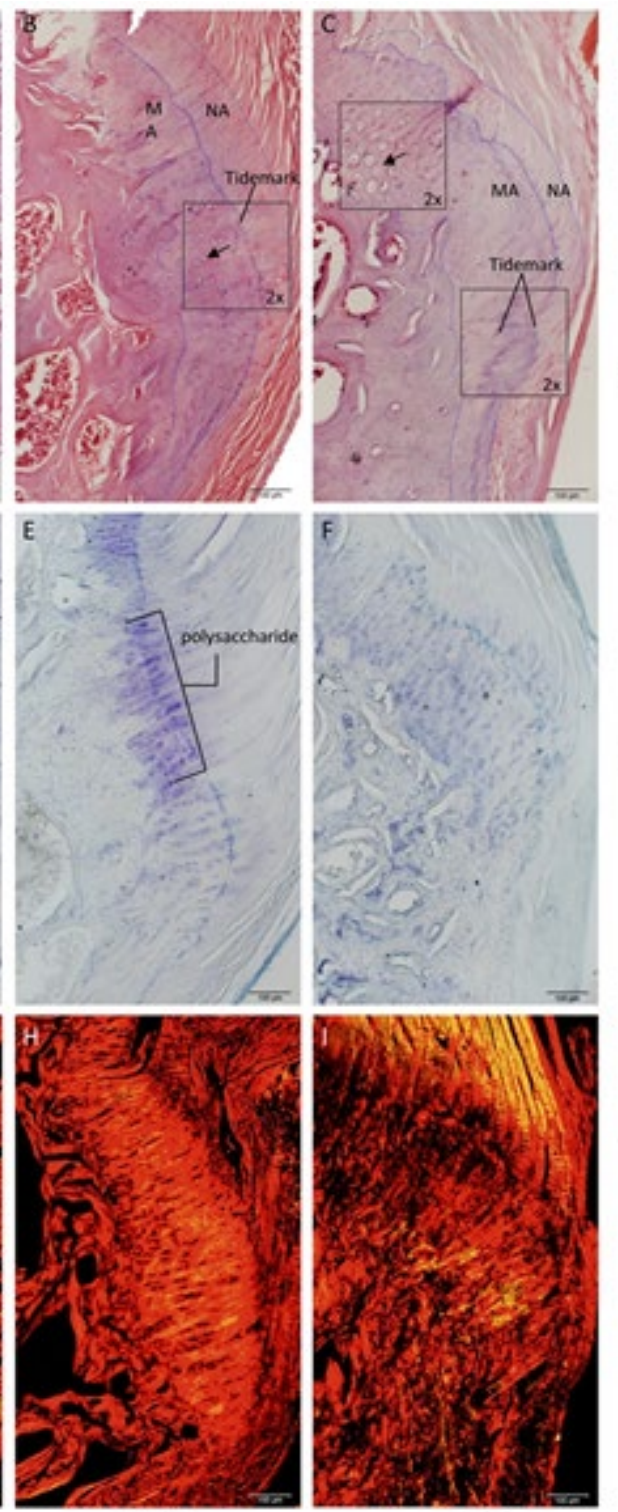

Mature

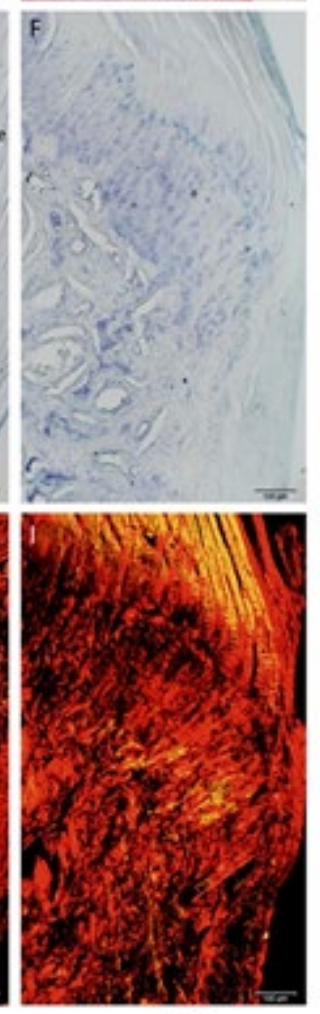

Aged
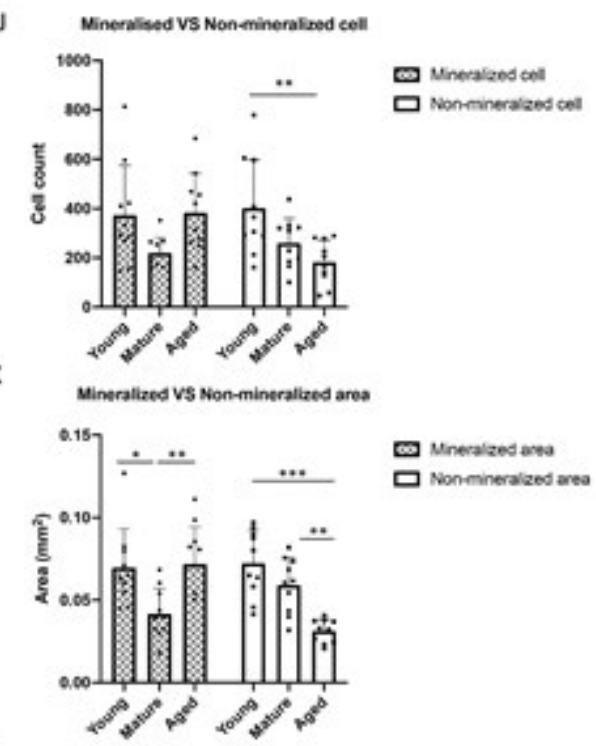

$\square$ Mineralizes awa
$\square$ Nonmineralized area

Mineralized Vs Non-mineralized ares thickness

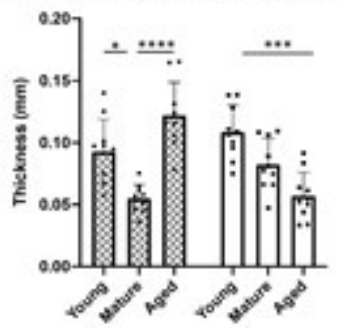

M

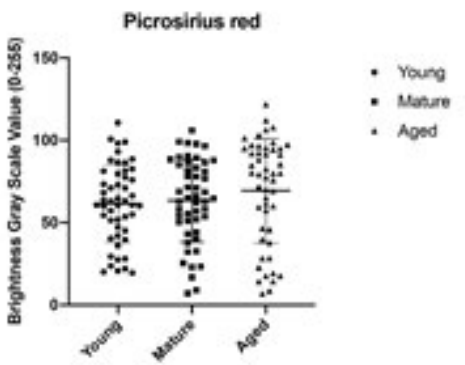

Figure 1. Histology of rotator cuff enthesis in young, mature and aged rats. Rotator cuff enthesis was stained with Hematoxylin \& Eosin (H\&E) for cellular structure (A, B, C). Mineralized area (MA) and nonmineralized area(NA) were divided by tidemark. The mineralized cells are small and distributed in pairs in young group but become larger and clustered with aging (black arrows), tidemark becomes rougher and deeper stained with age; Toluidine blue (TB) staining indicates decreasing polysaccharides with age (D, E, F). Cell counts and measures of areas were quantified based on H\&E staining and TB staining. Nonmineralized area $(\mathrm{K}, \mathrm{L})$ and cells $(\mathrm{J})$ decrease with age. Mineralized area and cell number show the lowest value in mature group. Brightness gray scale value (M) based on Picrosirius red staining $(G, H, I)$ indicates collagen alignments decrease with age, though it did not reach significance. (Young: 8-12 weeks, Mature: 12-15 months, Aged: 20-24 months). * $\mathrm{P}<0.05$, ** $\mathrm{P}<0.01$, *** $\mathrm{P}<0.001, * * * * \mathrm{P}<0.0001$. 
A

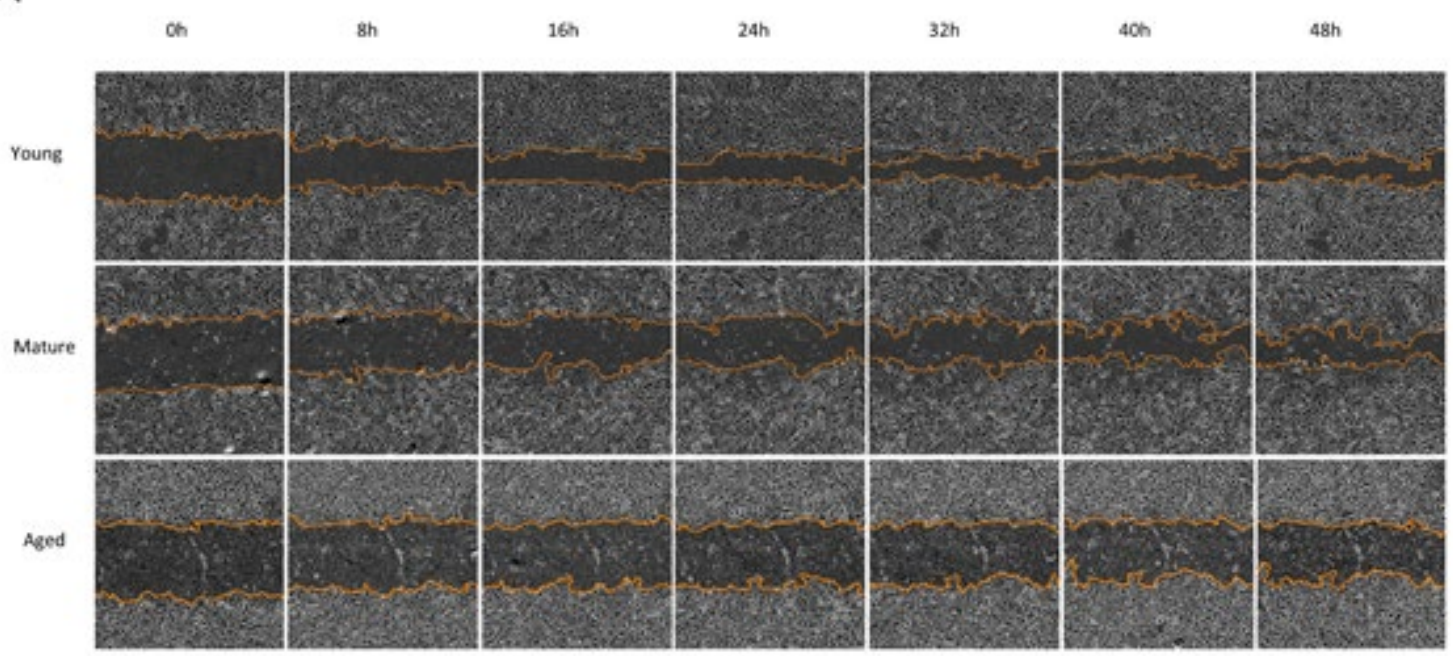

B

C

D
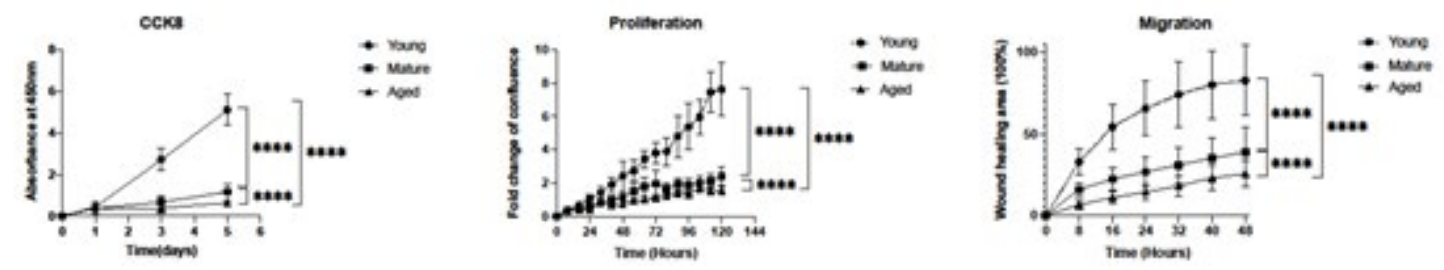

$E$
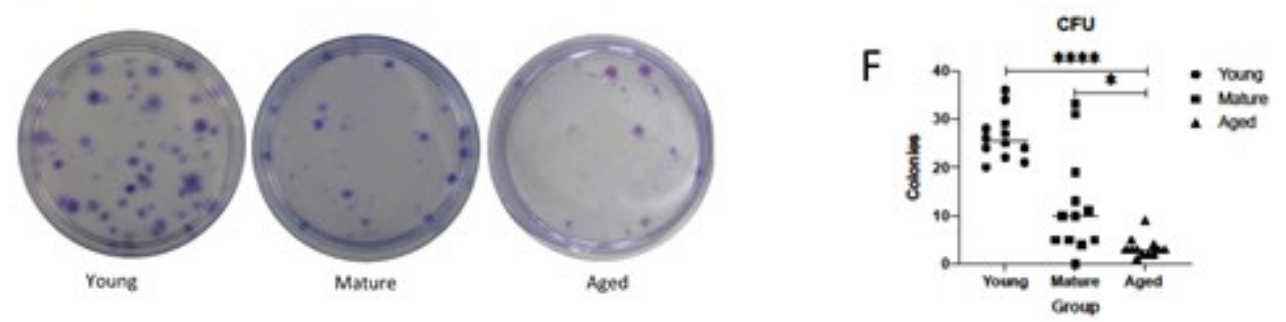

Figure 2. Proliferation and Migration assays of RCECs. Proliferation assays were performed with CCK8 proliferation assay method (B) and IncuCyte recording the fold change of confluence (C), significance was shown in both assays between all the age groups. Migration (D) assay results were illustrated as fraction of wound healing area. Young RCECs demonstrated significantly higher migration ability than mature and aged RCECs. Colony formation Units (E) were stained with crystal violet staining for visualization, more units were observed in young group (F) and these units are larger than that of mature and aged group. (Young: 8-12 weeks, Mature: 12-15 months, Aged: 20-24 months) * $\mathrm{P}<0.05$, **** $\mathrm{P}<0.0001$. 
$\mathrm{Y}-\mathrm{N}$

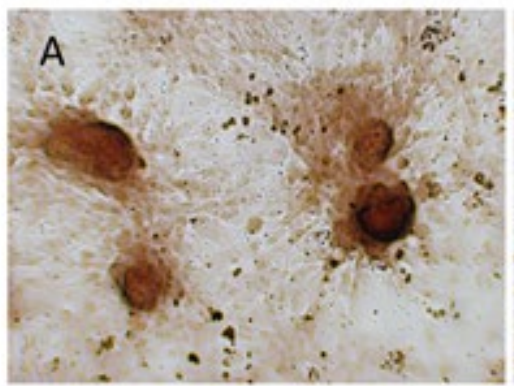

$\mathrm{Y}-\mathrm{O}$

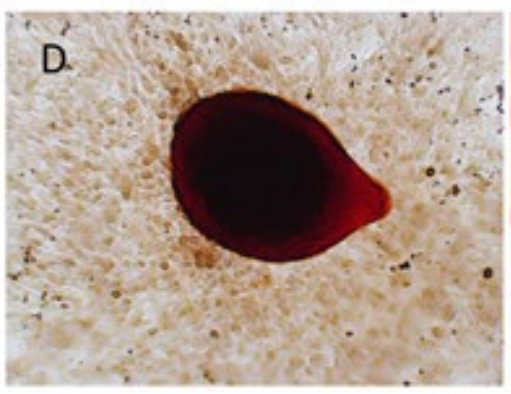

G
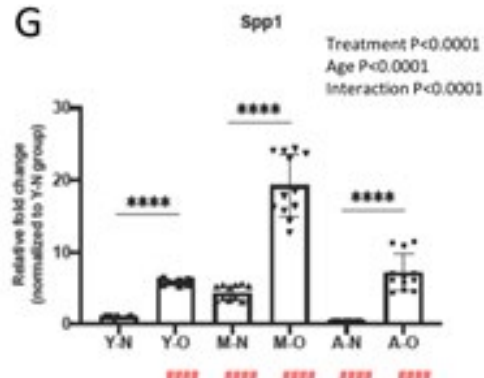

$\mathrm{M}-\mathrm{N}$

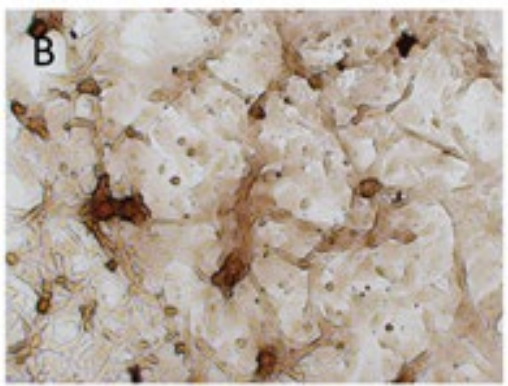

$\mathrm{M}-\mathrm{O}$
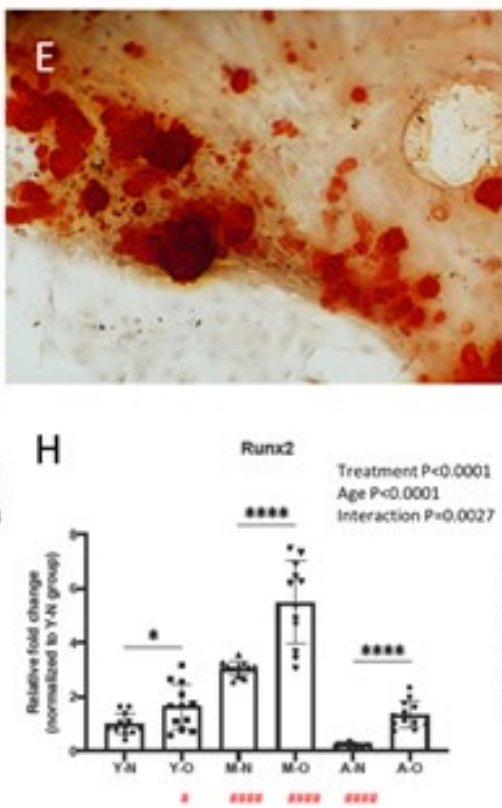

A-N
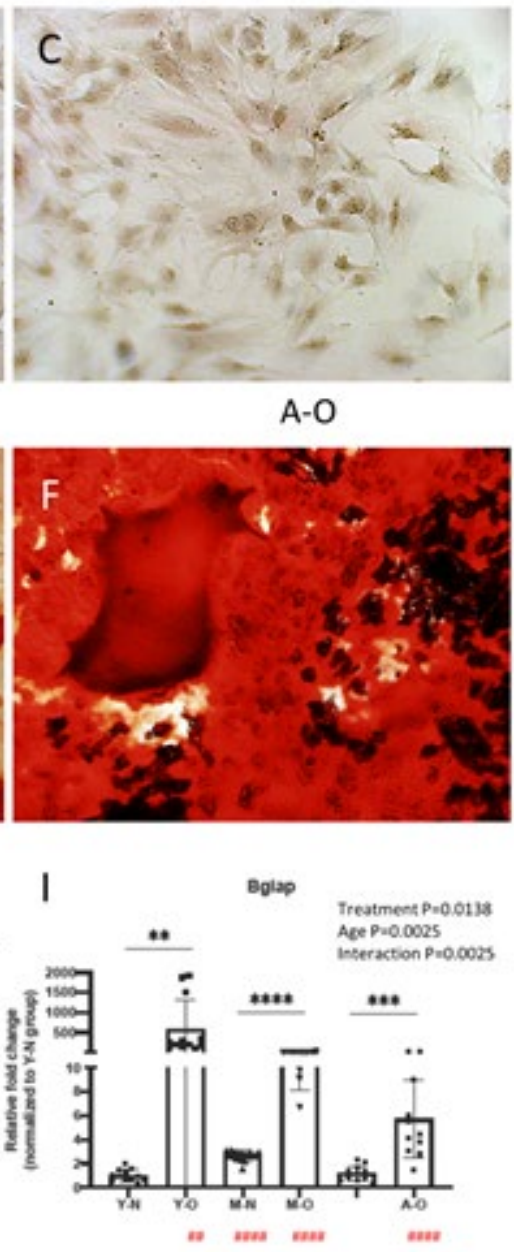

Figure 3. Osteogenic potential of RCECs at different ages. RCECs from different-age groups were successfully differentiated into osteocytes lineage under inducement. Red-stained calcium accumulation was formed in differentiated RCECs (DEF). The expression of osteogenic lineage specific gene was significantly increased (G-I). Treatment: the independent effect of inducement on gene expression. Age: the independent effect of age on gene expression. Interaction: the interaction of inducement and age on gene expression. YN: Young-nondifferentiated; Y-O: Young-osteogenesis; M-N: Mature- nondifferentiated; M-O: Matureosteogenesis; A-N: Aged-nondifferentiated; A-O: Aged-osteogenesis; */\# $\mathrm{P}<0.05, \quad * * / \# \# \mathrm{P}<0.01$ ， ***/\#\#\# $\mathrm{P}<0.001$ ，****/\#\#\#\# $\mathrm{P}<0.0001$ ，\# represents the significant differences with $\mathrm{Y}-\mathrm{N}$ group. 
$\mathrm{Y}-\mathrm{N}$

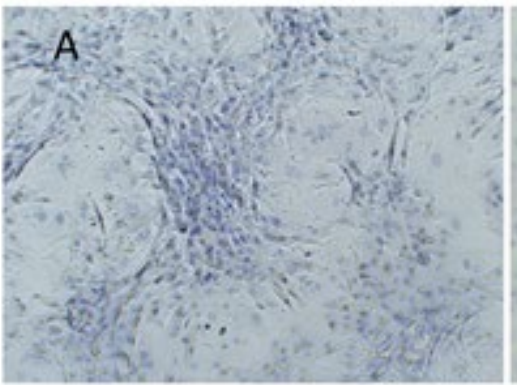

Y-A

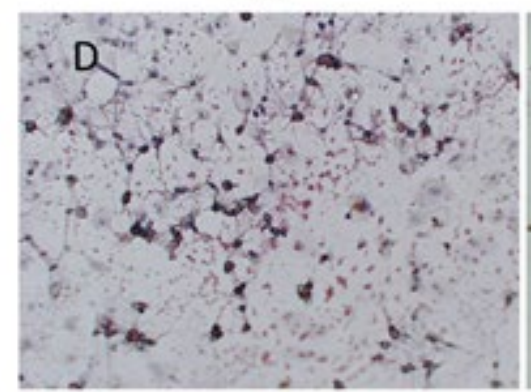

G
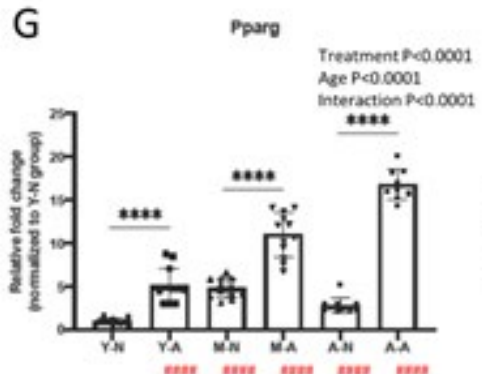

$\mathrm{M}-\mathrm{N}$

B

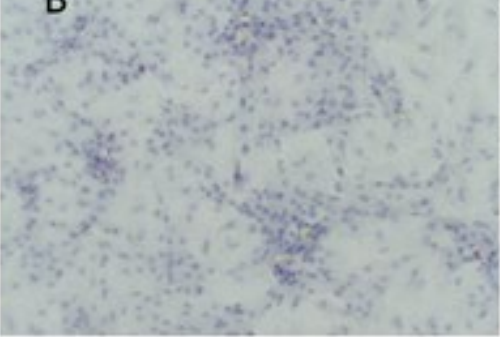

$\mathrm{M}-\mathrm{A}$

\section{$\mathrm{E}$}

H

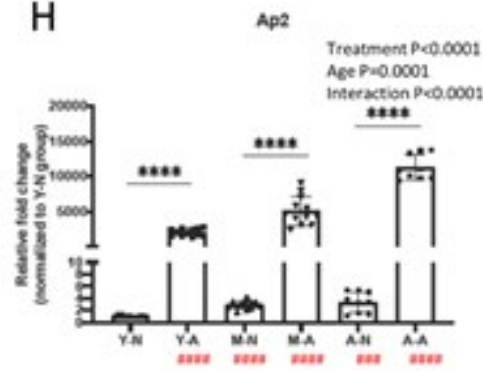

A-N

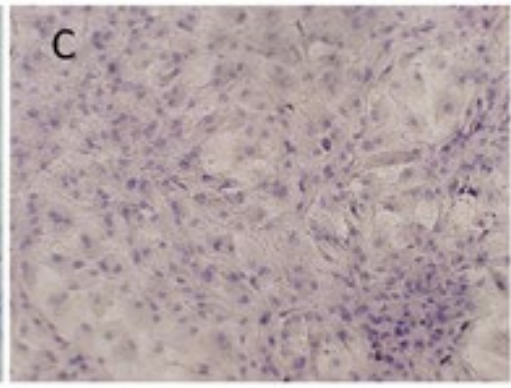

A-A
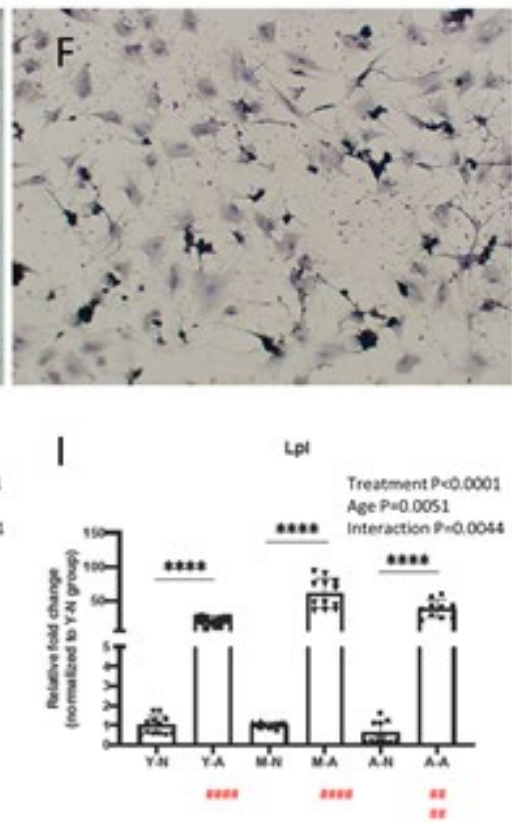

Figure 4. Adipogenic potential of RCECs at different ages. RCECs from different-age groups were successfully differentiated into adipocytes lineage under inducement. Red-stained lipids were formed in differentiated RCECs (DEF). The expression of adipogenic lineage specific gene was significantly increased (G-I). Treatment: the independent effect of inducement on gene expression. Age: the independent effect of age on gene expression. Interaction: the interaction of inducement and age on gene expression. Y-N: Youngnondifferentiated; Y-A: Young-adipogenesis; M-N: Mature- nondifferentiated; M-A: Mature-adipogenesis; A-N: Aged-nondifferentiated; A-A: Aged-adipogenesis; */\# $\mathrm{P}<0.05$, **/\#\# $\mathrm{P}<0.01$, ***/\#\#\# $\mathrm{P}<0.001$, ****/\#\#\#\# $\mathrm{P}<0.0001$, \# represents the significant differences with Y-N group. 
$\mathrm{Y}-\mathrm{N}$

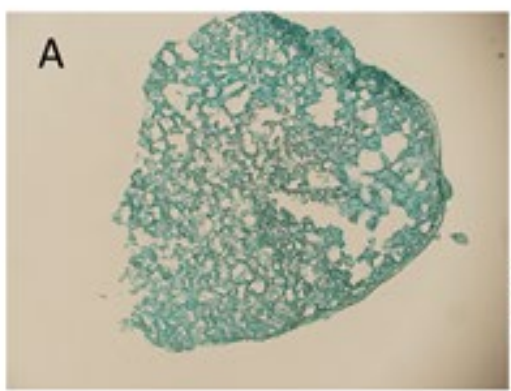

$\mathrm{Y}-\mathrm{C}$

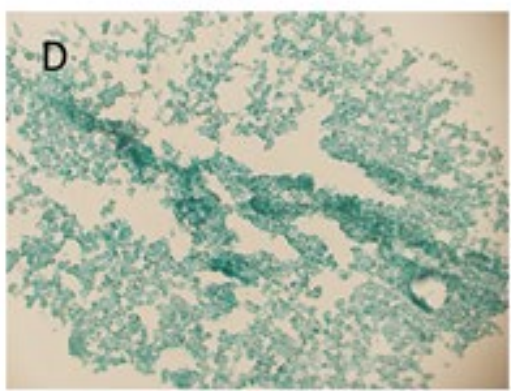

G

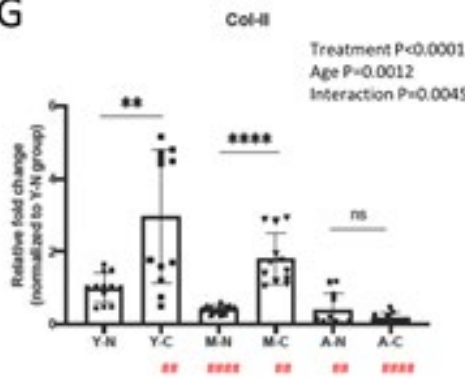

$\mathrm{M}-\mathrm{N}$

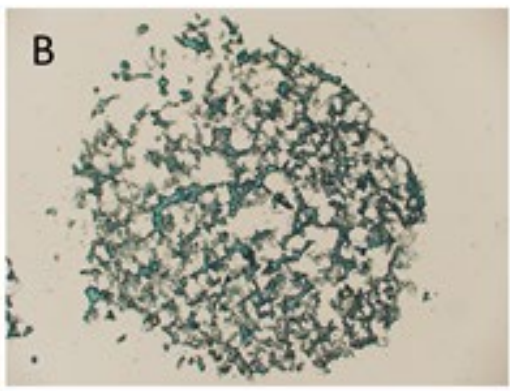

$\mathrm{M}-\mathrm{C}$

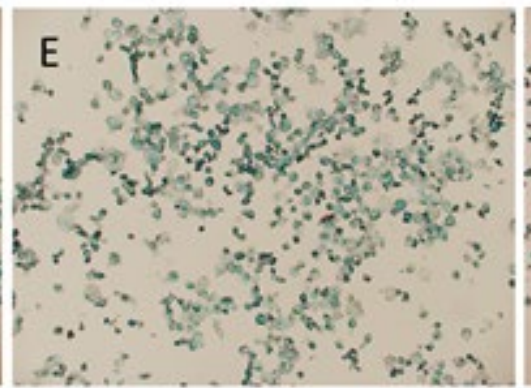

$\mathrm{H}$

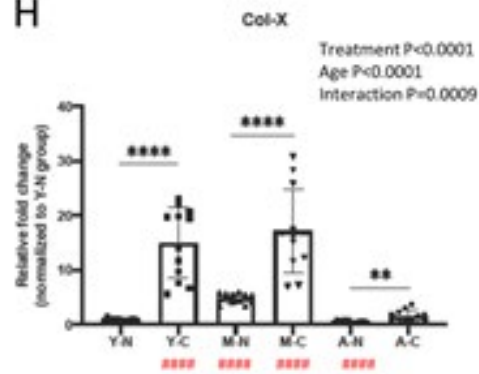

A-N

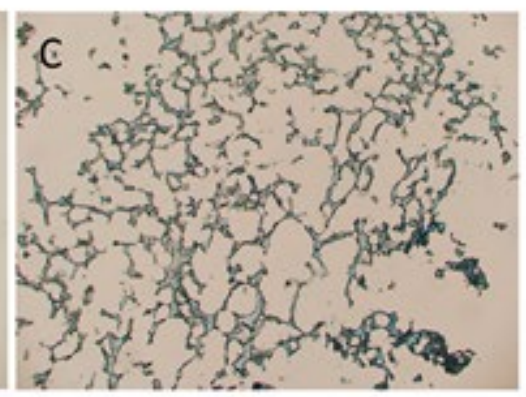

A-C
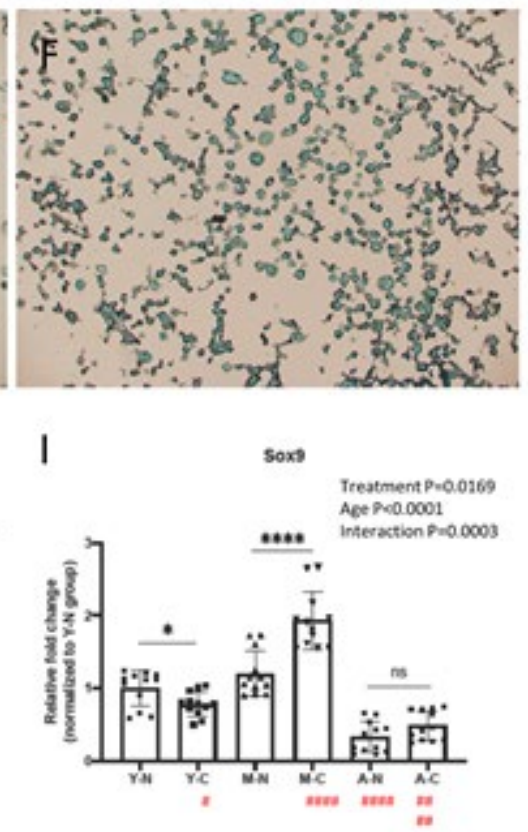

Figure 5. Chondrogenic potential of RCECs at different ages. RCECs from different-age groups were successfully differentiated into chondrocytes lineage under inducement. RCECs exhibited rounded, granular chondrocyte-like phenotype (DEF). The expression of chondrogenic lineage specific gene was significantly increased (G-I). Treatment: the independent effect of inducement on gene expression. Age: the independent effect of age on gene expression. Interaction: the interaction of inducement and age on gene expression. YN: Young-nondifferentiated; Y-C: Young-chondrogenesis; M-N: Mature- nondifferentiated; M-C: Mature chondrogenesis; A-N: Aged-nondifferentiated; A-C: Aged-chondrogenesis; */\# $\mathrm{P}<0.05, * * / \# \# \mathrm{P}<0.01$ ， ***/\#\#\# $\mathrm{P}<0.001$ ， ****/\#\#\#\# $\mathrm{P}<0.0001$ ， \# represents the significant differences with $\mathrm{Y}-\mathrm{N}$ group. 
$\mathrm{Y}-\mathrm{N}$

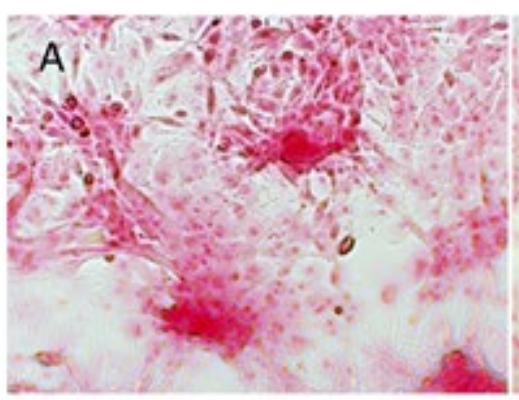

Y-T

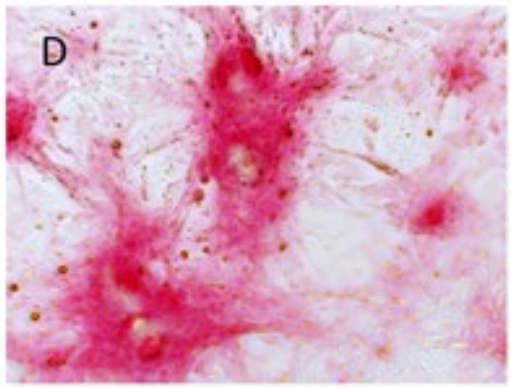

G

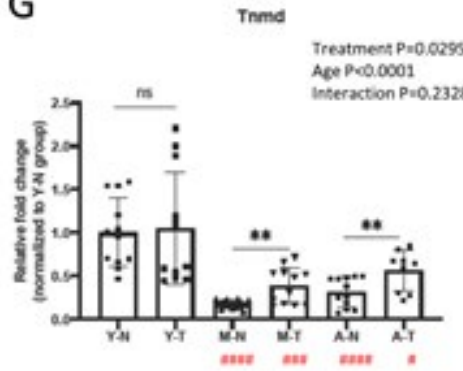

M-N

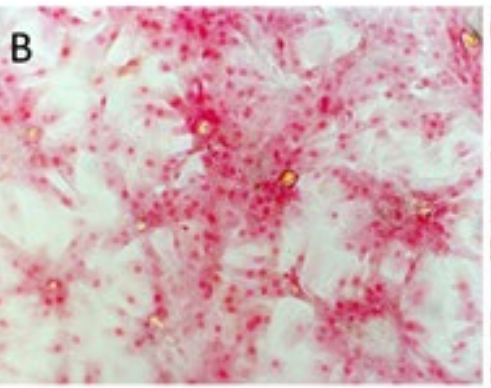

M-T

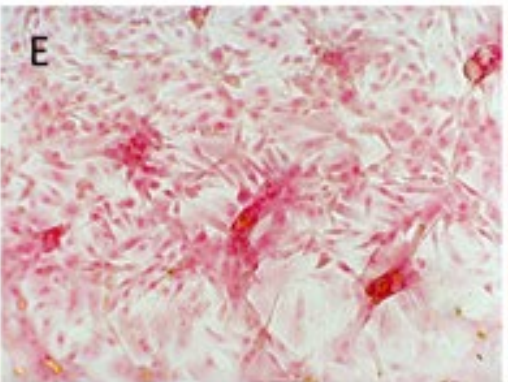

$\mathrm{H}$

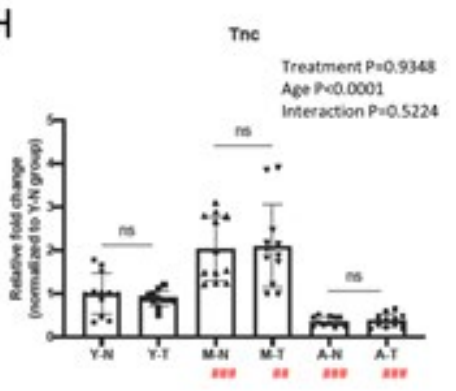

A-N

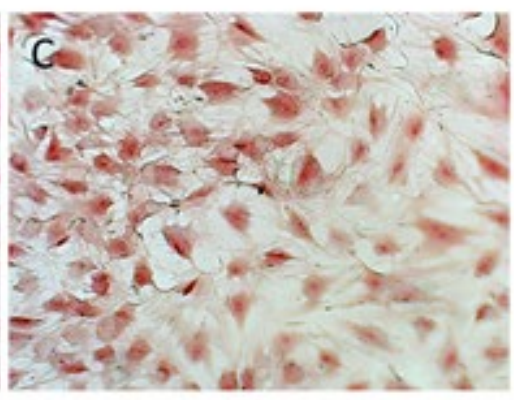

A-T

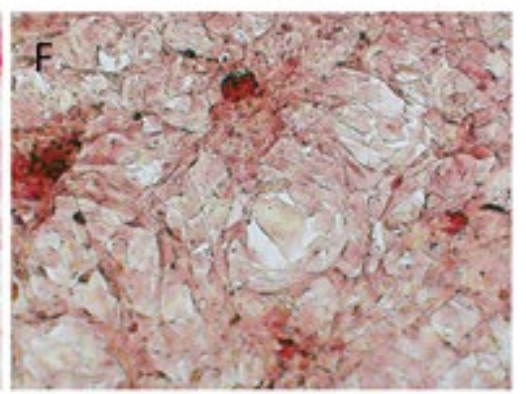

I

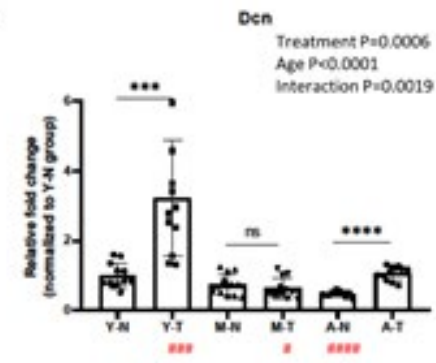

Figure 6. Tenogenic potential of RCECs in different ages. RCECs from different-age groups were successfully differentiated into tenocytes lineage under inducement. Young RCECs show strong collagen staining before and after tenogenic induction (A\&D). However, there was less red stained collagen matrix in the mature and aged groups $(\mathrm{BC} \& \mathrm{EF})$. The expression of chondrogenic lineage specific gene Tnmd was significantly higher in young groups, tenogenic inducement up regulated the expression of Tnmd in all groups, though there is no significance in young group $(G)$. Den was upregulated significantly in young differentiated group and aged group. Treatment: the independent effect of inducement on gene expression. Age: the independent effect of age on gene expression. Interaction: the interaction of inducement and age on gene expression. Y-N: Young-nondifferentiated; Y-T: Young-tenogenesis; M-N: Maturenondifferentiated; M-T: Mature-tenogenesis; A-N: Aged-nondifferentiated; A-T: Aged-tenogenesis; */\# $\mathrm{P}<0.05$ ，**/\#\# $\mathrm{P}<0.01$ ，***/\#\#\# $\mathrm{P}<0.001$ ， ****/\#\#\#\# $\mathrm{P}<0.0001$ ， \# represents the significant differences with Y-N group. 